\title{
Hypothyroidism masquerading as polymyositis
}

\author{
Shaltiel CABili \\ M.D. \\ NAOMI KAPLINSKY \\ M.D.
}

\author{
AMOS PINES \\ M.D. \\ OTTO FRANKL \\ M.D.
}

\begin{abstract}
Department of Medicine, The Chaim Sheba Medical Center; 52621 Tel-Hashomer, Israel, Affiliated to the TelAviv University Sackler School of Medicine, Tel-Aviv, Israel
\end{abstract}

\begin{abstract}
Summary
A group of patients is described who presented with proximal muscle weakness and elevated muscle enzymes. They were initially believed to have polymyositis and one of them was even treated as such over a long period of time. The patients were subsequently found to have hypothyroidism and responded well to thyroid hormone replacement.

Hypothyroidism should always be considered in the differential diagnosis of polymyositis. A polymyositislike picture has to be regarded as a symptom and not as a disease since it occurs in several metabolic, infectious, malignant and drug-induced diseases.
\end{abstract}

\section{Introduction}

Although myopathy and elevation of serum muscle enzymes are common in hypothyroidism (Astrom, Kugelberg and Muller, 1961; Comings, 1962; Norris and Panner, 1966; Fessel, 1968; Goldberg, 1970; Ramsay, 1974; Ingbar and Woeber, 1974; Hochberg et al., 1976; Klein et al., 1981), muscle involvement is usually mild and is often expressed only in abnormal laboratory findings.

Rarely, however, the myopathy is severe and might be the presenting symptom (Hochberg et al., 1976). Such cases can be misdiagnosed and mistreated as polymyositis. The purpose of this paper is to describe a series of patients initially presenting with a polymyositis-like syndrome who were subsequently found to have hypothyroidism.

\section{Case reports}

\section{Case 1}

A 49-year-old woman was referred to the rheumatology clinic because of muscle weakness, arthritis and swelling of the eyelids. A year earlier she had started to complain of pain, swelling and stiffness in the wrist and metacarpophalangeal joints, ankles and knees. Gradually she also developed swelling of the eyelids and difficulties in raising her arms and getting up from a chair.

Physical examination on admission revealed a hoarse voice, coarse skin, difficulties in arising from a low lounge chair, proximal muscle tenderness and weakness in both upper and lower extremities, swollen eyelids and an incisional hernia in the abdomen.

Laboratory examinations showed erythrocyte sedimentation rate (ESR) $20 \mathrm{~mm} / \mathrm{hr}$, haemoglobin, leucocytes, blood urea, and glucose normal; creatine kinase (CK) 128-190 u./dl (isoenzyme MM) (normal under $70 \mathrm{u} . / \mathrm{dl}$ ), lactic dehydrogenase (LDH) 222-313 u./dl (normal under $200 \mathrm{u} . / \mathrm{dl}$ ), glutamic oxaloacetic transaminase (SGOT) 19 u./dl (normal under $16 \mathrm{u} . / \mathrm{dl})$.

The clinical impression was that the patient suffered from polymyositis, and this was supported by the elevated muscle enzymes. The patient was referred to the hospital for a muscle biopsy and an electromyogram. At that time the Achilles tendon reflex showed slow relaxation and, after questioning, cold sensitivity, constipation and weight gain became evident. Thyroid gland function tests revealed primary hypothyroidism with thyroxine $\left(\mathrm{T}_{4}\right)$ (Sephadex) $0.3-1.3 \mu \mathrm{g} / \mathrm{dl}$ (normal 4.5-10.7 $\mu \mathrm{g} / \mathrm{dl}$ ), elevated thyroid stimulating hormone (TSH), $2 \mathrm{hr}$ radioactive iodine uptake of $4 \%$, thyroglobulin antibodies $1: 166$, thyroid microsomal antibodies $1: 1000$.

The patient was treated with L-thyroxine in gradually rising doses to $150 \mu \mathrm{g} /$ day. Her condition improved gradually, she lost weight, the puffiness of the face and eyelids regressed, muscle strength returned to normal and so did the serum muscle enzymes. 


\section{Case 2}

A 55-year-old woman had been suffering from classical seropositive rheumatoid arthritis since the age of 49 , and received crysotherapy and several non-steroidal drugs, with good response. Proximal muscle weakness and pain developed a few weeks before her admission with puffiness of the face. Polymyositis was suspected since overlapping of rheumatoid arthritis and polymyositis is known to occur. Muscle enzymes were elevated and the patient was referred to the ward for further investigation.

Her face was swollen and pale, the thyroid was not palpable and the second component of the Achilles tendon reflex was very slow; proximal muscle weakness in the upper and lower extremities and signs of inactive rheumatoid arthritis in the upper limb joints were noted.

The electrocardiogram showed low voltage in all leads.

Laboratory tests showed ESR $30 \mathrm{~mm} / \mathrm{hr}, \mathrm{CK} 92$ u./dl, (isoenzymes MM), LDH 340 u./dl, SGOT 21 u./dl, cholesterol $340 \mathrm{mg} / \mathrm{dl}(8.84 \mathrm{mmol} / \mathrm{l})$; triglycerides, haemoglobin, leucocytes, urea, creatinine, serum proteins, alkaline phosphatase, bilirubin and urinalysis were all normal. Thyroid function tests revealed the typical findings of hypothyroidism with $\mathrm{T}_{4}$ (Sephadex) undetectable, $\mathrm{T}_{3}$ resin uptake $33 \%$ (normal under 60\%), free thyroxine index (FTI) 0 , (normal 3.8-12.8), elevated TSH, idodine uptake 5\% after $2 \mathrm{hr}$ and $7 \%$ after $24 \mathrm{hr}$. Thyroid scan showed a small gland.

L-thyroxine $125 \mu \mathrm{g} /$ day was administered with gradual improvement. Muscle strength was regained and serum muscle enzymes returned to normal.

\section{Case 3}

A 42-year-old teacher was admitted for evaluation of severe muscle weakness mainly of the thighs and shoulders, which appeared following a tour in the country. Physical examination confirmed the findings of proximal muscle weakness and tenderness with no other significant findings.

Laboratory tests showed marked elevation of serum muscle enzymes-SGOT 64-105 u./dl, LDH 370-460 u./dl, CK 80-140 u./dl. Creatine excretion in the urine ranged between 225 and $305 \mathrm{mg} / 24 \mathrm{hr}$ (normal under $40 \mathrm{mg} / 24 \mathrm{hr}$ ). Virological studies of blood and stool were negative. Electromyography was normal, as well as a biopsy from the gastrocnemius which was examined by light microscopy. The patient was discharged with a presumptive diagnosis of polymyositis and was treated with prednisone $\mathbf{4 0}$ $\mathrm{mg} /$ day. After 4 months of steroid treatment, there was no improvement, and the drug was stopped when cushingoid features developed. A short course of methotrexate was also ineffective.
The patient was readmitted 6 months later because $\frac{\mathbb{Q}}{\varnothing}$ of severe sunburns of the thighs and shoulders. On $c$. physical examination there were no new findings $\overrightarrow{\vec{F}}$ and laboratory tests still showed elevated muscle $\stackrel{5}{\rightarrow}$ enzymes. In the following year the muscle weakness and pain became worse and interfered with his daily activities. He became tense and depressed and $\frac{\mathcal{N}}{\sigma}$ required psychiatric treatment. Finally, he was ad- $\stackrel{\mathbb{Q}}{\varrho}$ mitted to hospital for re-evaluation.

This time, physical examination revealed puffiness $\vec{\theta}$ of the face, a coarse dry skin and lengthening of the relaxation phase of the tendon reflexes. The relevant $\vec{\omega}$ laboratory tests were ESR $22 \mathrm{~mm} / \mathrm{hr}, \mathrm{CK}$ 1700-2900 u./dl, SGOT 90 u./dl, LDH 776 u./dl, cholesterol 8 $325 \mathrm{mg} / \mathrm{dl}$. (8.45 mmol/1), mild macrocytic anaemia. Thyroid function tests showed the findings of $\infty$ primary hypothyroidism- $\mathrm{T}_{4} 0.6 \mu \mathrm{g} / 100 \mathrm{ml}, \mathrm{T}_{3}$ resin $\%$ uptake $37 \%$, FTI 0.3 , elevated TSH levels; iodine uptake by the gland was practically zero.

The patient was treated with thyroid USP $100 \mathrm{mg}$ of three times daily. A month later there was marked $\frac{}{5}$ improvement of all the symptoms and 2 months $\vec{D}$ later still the patient became asymptomatic with no $\mathbb{D}$ laboratory abnormalities. The muscle strength and $\frac{\mathbb{T}}{\Phi}$ the thyroid indices were normal.

\section{Discussion}

There is a well-known association between hyp thyroidism and muscle disease, ranging from asymp= 을 tomatic elevation of serum muscle enzymes to severe clinical muscle disease (Astrom et al., 1961; Comings, 1962; Norris and Panner, 1966; Fessel, 1968; Gold- ֶ berg, 1970; Ramsay, 1974; Ingbar and Woeber, 1974; $\stackrel{\mathbb{Q}}{\Omega}$ Hochberg et al., 1976; Klein et al., 1981). Muscle $\overrightarrow{\vec{P}}$ weakness of the shoulder and the pelvic girdles is $\frac{9}{3}$ often found in hypothyroidism. It is sometimes accompanied by pain, stiffness and polymyositis-like symptoms. Our patients demonstrate the pitfalls in the diagnosis of hypothyroidism when it presents as 3 . polymyositis. This probably springs from the insidious development of hypothyroidism on the one hand 3 and the fact that the muscle symptoms are sometimes so severe as to dominate the clinical picture.

Despite this overt muscular disease, muscle biopsy 을 and electromyography are usually normal (Hochberg et al., 1976). The picture can be even more complicated when other diseases with an overlapping clinical spectrum coexist, such as rheumatoid arthri- o tis in our second patient and in the patient reported $N$ by Bohan and Peter (1975). All these features can $\underset{\mathrm{W}}{ }$ lead to a low index of suspicion towards the true $\sigma$ diagnosis, whose recognition can thus be delayed.

At times, hypothyroid myopathy simulates all the $\frac{0}{\mathbb{C}}$ diagnostic criteria of polymyositis, namely proximal $\stackrel{\leftrightarrow}{+}$ muscle weakness, elevation of serum muscle enzymes 0 (Ramsay, 1974; Ingbar and Woeber, 1974; Hochberg 
et al., 1976; Klein et al., 1981; Santo, Hibi and Kawazura, 1963; Graig and Smith, 1965; Fleischer, McConahey and Pankow, 1965; Griffiths, 1965; Ekbom, Hed and Herdenstan, 1966; Goto, 1974), myopathic electromyographic changes (Ramsay, 1974) and even muscle biopsy, compatible with polymyositis, showing necrosis, centralization of sarcolemmal nuclei and fibre basophilia (Astrom et al., 1961; Comings, 1962; Norris and Panner, 1966; Fessel, 1968). However, the clinician should regard polymyositis as a symptom rather thar a definite disease entity, thus prompting a search for a diagnosis usually unrelated to the primary muscle disease. Hypothyroidism, malignancy, infections (Pittsby, Shearn and Kaufman, 1978; Levin, Gardner and Waldvogel, 1971), sarcoidosis (Silverstein and Siltzbach, 1969), and certain drugs (Langer and Levy, 1968; Michael and Mitch, 1975; Schraeder, Peters and Dahl, 1972) are all well-known causes of myositic syndromes, masquerading as primary muscular disease.

The hallmark of hypothyroid myopathy is the complete clinical recovery and resolution of the laboratory abnormalities following thyroid replacement. This is well demonstrated in all our patients, thus excluding other possible unrelated causes of the myositic syndrome.

Since hypothyroidism with muscle involvement is a treatable disease with a favourable prognosis, thyroid function tests should be performed in all the patients with an unexplained myopathy.

\section{References}

ASTrom, K.E., Kugelberg, E. \& MUller, R. (1961) Hypothyroid myopathy. Archives of Neurology, 5, 472.

Bohan, A. \& PETER, J.B. (1975) Polymyositis and dermatomyositis. New England Journal of Medicine, 292, 344.

Comings, D.E. (1962) Myxedema with Erb's limb girdle muscular dystrophy. Archives of Internal Medicine, 109, 724.

ExbOM, K., Hed, R. \& Herdenstan, C.G.P. (1966) The serum creatine-phosphokinase activity and the Achilles reflex in hyperthyroidism and hypothyroidism. Acta Medica Scandinavia, 179, 433.
FESSEL, W.J. (1968) Myopathy of hypothyroidism. Annals of Rheumatic Diseases, 27, 590.

Fleischer, G.A., McConAhey, W.M. \& PANKow, M. (1965) Serum creatine-kinase, lactic dehydrogenase and glutamicoxaloacetic transferase in thyroid diseases and pregnancy. Proceedings of the Staff Meetings of the Mayo Clinic, 40, 300.

GolDBERG, D.N. (1970) Hypothyroidism presenting with musculoskeletal symptoms. Annals of Rheumatic Diseases, 29, 10.

GoTo, I. (1974) Serum creatine phosphokinase isoenzymes in hypothyroidism, convulsion, myocardial infarction and other diseases. Clinica Chimica Acta, 52, 27.

GRAIG, F.A. \& SMITH, J.C. (1965) Serum creatine phosphokinase activity in altered thyroid states. Journal of Clinical Endocrinology, 25, 723.

GRIFFITHS, P.D. (1965) Serum enzymes in diseases of the thyroid gland. Journal of Clinical Pathology, 18, 660.

HoChBERG, M.C., KOPPES, G.M., EDWARDS, C.Q., BARNES, H.V.\& ARNETT, C.F. JR (1976) Hypothyroidism presenting as a polymyositis-like syndrome. Journal of the American Rheumatic Association, 19, 1363.

INGBAR, S.H. \& WOEBER, K.A. (1974) The thyroid gland. In: Textbook of Endocrinology (ed. by Williams, R.H.), pp. 95-232. W. B. Saunders, Philadelphia.

Klein, I., PARker, M., Sherbert, R., AYyar, D.R. \& LeVey, G.S. (1981) Hypothyroidism presenting as muscle stiffness and pseudohypertrophy: Hoffman's syndrome. American Journal of Medicine, 70, 891.

LANGER, T. \& LEVY, R.I. (1968) Acute muscular syndromes associated with administration of clofibrate. New England J,ournal of Medicine, $279,856$.

LeVIN, M.J., GARDNeR, D. \& WaldVogel, F.A. (1971) 'Tropical' polymyositis: an unusual infection due to Staphylococcus aureus. New England Journal of Medicine, 284, 196.

MiCHAEL, J.R. \& MITCH, W.E. (1975) Reversible renal failure and myositis caused by phenytoin hypersensitivity. Journal of the American Medical Association, 236, 2773.

NORRIS, F.H. \& PANNER, N.J. (1966) Hypothyroid myopathy. Archives of Neurology, 14, 574.

PitTSby, R.A., Shearn, M.A. \& Kaufman, L. (1978) Acute hepatitis B simulating dermatomyositis. Journal of the American Medical Association, 239, 259.

RAMSAY, L. (1974) Thyroid Disease and Muscle Dysfunction. Year Book Medical Publishers, Chicago.

SANTo, M., HibI, I. \& KaWAZURA, M. (1963) Creatine phosphokinase levels in hypothyroidism. Lancet, it, 252.

SChraeder, P.L., PeTers, H.A. \& DAhL, D.S. (1972) Polymyositis and penicillamine. Archives of Neurology, 27, 450.

SiLverSTEIN, A. \& SILTZBACH, L.E. (1969) Muscle involvement in sarcoidosis. Archives of Neurology, 21, 235. 